NBER WORKING PAPER SERIES

\title{
THE ROLE OF ASSETS IN PLACE: LOSS OF MARKET EXCLUSIVITY AND INVESTMENT
}

\author{
Matthew J. Higgins \\ Mathias J. Kronlund \\ Ji Min Park \\ Joshua Pollet \\ Working Paper 27588 \\ http://www.nber.org/papers/w27588
NATIONAL BUREAU OF ECONOMIC RESEARCH
1050 Massachusetts Avenue
Cambridge, MA 02138
July 2020

We thank IMS Health Incorporated, now IQVIA, for their generous support and access to their data. The statements, findings, conclusions, views, and opinions contained and expressed herein are not necessarily those of IQVIA, IMS Health Incorporated or any of its affiliated or subsidiary entities. The statements, findings, conclusions, views, and opinions contained and expressed in this article are based in part on data obtained under license from the following IMS Health Incorporated or affiliate information service(s): IMS Midas ${ }^{\mathrm{TM}}$ and IMS NDTI. Higgins acknowledges support from the Sorenson Center for Discovery and Innovation. The views expressed herein are those of the authors and do not necessarily reflect the views of the National Bureau of Economic Research.

NBER working papers are circulated for discussion and comment purposes. They have not been peerreviewed or been subject to the review by the NBER Board of Directors that accompanies official NBER publications.

(C) 2020 by Matthew J. Higgins, Mathias J. Kronlund, Ji Min Park, and Joshua Pollet. All rights reserved. Short sections of text, not to exceed two paragraphs, may be quoted without explicit permission provided that full credit, including $\odot$ notice, is given to the source. 
The Role of Assets In Place: Loss of Market Exclusivity and Investment Matthew J. Higgins, Mathias J. Kronlund, Ji Min Park, and Joshua Pollet NBER Working Paper No. 27588

July 2020, Revised August 2020

JEL No. D92,G31,G32,G35,L65,O30

\begin{abstract}
$\underline{\text { ABSTRACT }}$
We utilize a novel identification strategy to analyze the impact of assets in place on firms' decisions for future projects. We exploit the context in the pharmaceutical industry, where the loss of market exclusivity for a branded drug can be used to separate the impact of cash flows generated by a firm's current assets in place from the characteristics of its future investment opportunities. We first show that around the exclusivity losses in our sample of large drugs, the affected firms' profitability drop significantly. The timing of this profitability decrease was predetermined many years ago, and therefore, arguably independent of current investment opportunities. Nevertheless, we find that R\&D spending drops by approximately $25 \%$ over two years following the loss of exclusivity. We also find that stock repurchases and cash balances decline significantly. Our findings do not support the predictions of traditional capital budgeting, but are more consistent with the pecking order theory. These results further point to a lack of long-term lifecycle management that could mitigate the effect of predictable negative shocks to cash flows.
\end{abstract}

Matthew J. Higgins

David Eccles School of Business

University of Utah

1731 E Campus Center Drive

Salt Lake City, UT 84112

and Max Planck Institute for

Innovation and Competition

and also NBER

matt.higgins@eccles.utah.edu

Mathias J. Kronlund Freeman

School of Business Tulane

University

7 McAlister Dr

New Orleans, LA 70118

mkronlund@tulane.edu
Ji Min Park

Gies College of Business

University of Illinois at Urbana-Champaign

607 E Gregory Drive

Champaign, IL 61820

jpark358@illinois.edu

Joshua Pollet

Gies College of Business

University of Illinois at Urbana-Champaign

4039 BIF

515 E. Gregory Drive

Champaign, IL 61820

pollet@illinois.edu 


\section{Introduction}

Many factors contribute to a firm's investment and financing decisions. The baseline model is provided by traditional capital budgeting. Firms invest to undertake positive net-presentvalue (NPV) projects with the funds for these investments being raised from either internal or external sources of financing without frictions (Modigliani and Miller (1958)). Alternatively, in the presence of asymmetric information, external financing is costly, and firms may optimally choose to forgo a positive-NPV project if the project cannot be financed using internal cash flows or pre-existing cash on the firm's balance sheet (Myers and Majluf (1984)). ${ }^{1}$ Costly external finance leads to a pecking order theory for financing a firm's investment, whereby available internally generated cash or cash flows are used before issuing external debt or equity to finance new projects.

It is typically challenging to distinguish between these theories' relative contributions and assess the role of financing frictions on firms' investments. This is because it is difficult to separate the impact from changes that affect cash flows available for investment (often generated from a firm's assets in place), from the changing valuations of a firm's current investment opportunities. In other words, whenever a firm's current profitability falls, the NPV of its investment opportunities tends to decline at the same time, thus reducing the benefits of such investment. In this context, even a model with frictionless investment would predict less investment in the face of lower cash flows.

The expiration of pharmaceutical patents protecting a branded drug or the resulting loss of market exclusivity represents a unique situation that can distinguish between these two theories. Immediately following the loss of market exclusivity, other firms may directly compete by providing a bioequivalent generic version of the original drug that does not require clinical testing as part of the approval process created by the Food and Drug Administration

\footnotetext{
${ }^{1}$ There exist other mechanisms that also can affect external financing decisions; for instance, market timing predicts that firms issue and repurchase equity to take advantage of mispricing (Baker, Ruback, and Wurgler (2007); Stein (1996)). However, a market-timing hypothesis does not make precise predictions about the relation between the timing of investment or $R \& D$ and profitability patterns.
} 
(FDA). ${ }^{2}$ This form of competition from generic entry dramatically reduces revenue for the affected branded drug, and consequently, the profitability of the branded firm (e.g., Reiffen and Ward (2005); Branstetter, Chatterjee, and Higgins (2016)).

Crucially, it is implausible for the timing of the change in cash flow associated with the loss of market exclusivity to contain information about future investment opportunities for the affected firm. The timing is pre-determined based on the drug's patents, which were granted many years prior. The fact that a drug losses exclusivity on a specific date has no bearing on the future profitability of other drugs in the affected firm's development pipeline. ${ }^{3}$ This implies a predictable change in the cash flow from assets in place, which is caused by the loss of market exclusivity. This change is plausibly exogenous to current investment opportunities to develop new drugs by the firm. ${ }^{4}$ The impact of these losses of market exclusivity is often also economically large; thus, we expect that they may cause measurable effects on investment if firms indeed act as if they are financially constrained.

To study the effects of these loss-of-market-exclusivity events, we follow the methodology in Gormley and Matsa (2011) to construct cohorts of peer firms. Treated firms in each cohort consists of firms that experience a loss of market exclusivity in that quarter, and these firms are then compared to peer control firms that did not suffer such a loss. We compare these groups of firms over eight quarters before and after the loss by employing a difference-in-differences approach.

Our results indicate that quarterly firm revenues decrease by more than three percentage

\footnotetext{
${ }^{2}$ To be more precise, this is accurate for chemical-based drugs as opposed to biologic-based drugs. For this paper's purposes, our focus will be on the loss of market exclusivity (i.e., patent protection) and subsequent generic entry surrounding chemical-based drugs. The current regulatory environment faced by pharmaceutical companies in the U.S. and the delineation between chemical- and biologic-based drugs will be discussed in Section 2.1.

${ }^{3}$ As a consequence of external technology markets, including licensing, merger and acquisitions, the patent holder at expiration was often not responsible for the original patent application or the underlying research.

${ }^{4}$ Multiple patents often protect drugs, and patent protection can be extended under particular circumstances. Furthermore, some patents are subject to "Paragraph IV" legal challenges by generic manufactures. These challenges can occur anytime between the end of the regulatory data exclusivity period and the end of patent protection. For a more complete discussion, see Voet (2016). Our empirical analysis examines corporate decisions over sufficiently long time windows before and after the expected date of patent expiration; any residual uncertainty is unlikely to have an appreciable impact on the timing patterns that we find.
} 
points, as scaled by lagged total assets, following the loss of market exclusivity for a branded drug. Because the average firm in our sample has quarterly drug revenue scaled by lagged assets of approximately 17 percent, this decrease is approximately 20 percent of the baseline revenue. We find even larger effects when we further exclude any events where the branded drugs are relatively less economically important (i.e., those that generate less than 1 percent of a firm's revenue before the loss of exclusivity); these tests thus focus on the relatively more significant events. We observe similar patterns of decreases in firm profitability and cash flows, especially around these larger events.

Since new investment and research and development $(R \& D)$ are critically important for firms in the pharmaceutical industry, we expect these corporate decisions to reflect the rational assessment of investment opportunities and any trade-off imposed by external financing. According to Acemoglu and Linn (2004) and Dubois, Mouzon, Scott-Morton, and Seabright (2015), pharmaceutical companies do respond to the predictable changes in demand induced by demographics. The industry as a whole develops more drugs for categories that are predicted to have an increase in patients. Additionally, Ellison and Ellison (2011) show that pharmaceutical companies use advertising expenditures in a sophisticated manner to strategically deter entry. Based on these findings, it certainly appears as if firms in this industry are sophisticated actors that implement corporate decisions using a logical evaluation of the available investment opportunities so that when a firm's internal cash flows fall, it also reduces investments in new projects.

How should firm decisions regarding investment opportunities be affected by a substantial and predictable decrease in revenue and profitability generated by assets in place? If traditional capital budgeting largely explains firm decisions, then investment and R\&D expenditures should only depend on whether current projects have an NPV that is greater than zero. Expenditures supporting investment opportunities should be unrelated to the timing of the loss of market exclusivity. Moreover, the timing for raising external financing should be positively related to the timing of these expenditures on investment opportunities. By 
contrast, if external financing is costly, then revenues and profitability from assets in place should be positively associated with higher expenditures on investment opportunities.

Our evidence indicates that R\&D decreases significantly during the eight quarters following the loss of market exclusivity. During these eight quarters, quarterly R\&D expenses, normalized by lagged assets, decrease by about 0.6 percentage points (relative to a sample mean of $2.36 \%$ ) for the affected firms, when compared to peer firms that do not experience a loss of market exclusivity at the same time. In other words, R\&D is around 25 percent lower for the affected firms following the loss of market exclusivity. The estimated impact on capital expenditures is also negative, but this effect is economically smaller and not statistically significant.

Next, we examine the impact of this predictable decrease in cash flows from the loss of market exclusivity on the firms' financing and cash policies. First, consistent with almost any theory in which internal pre-existing cash balances are deployed to support the firm when it suffers a negative shock to cash flows, we find that cash balances significantly decrease. We also find that total shareholder payouts decrease following the loss of market exclusivity. However, this effect is driven entirely by a sharp cutback of share repurchases. The decrease is approximately 0.5 percentage points relative to the mean of 0.68 percent. This pattern is consistent with the pecking order theory in which the firm adjusts cash and payout policy to finance investment before issuing new securities. By contrast, we find some evidence of a slight increase in dividends after these events. However, this effect is mostly driven by events that involve smaller and thus less-economically important drugs.

The pattern linking the loss of market exclusivity and external finance is more nuanced. We find some evidence that debt issuances increase and equity issuances decrease around these loss-of=exclusivity events, but only for firms that are relatively more financially constrained. On the other hand, firms that are likely to be less financially constrained (measured as the largest firms in the sample), do not exhibit any patterns regarding security issuance 
following the loss of market exclusivity. The decline in R\&D we observed is also lower for these relatively less constrained firms.

The paper presents several tests to ensure the robustness of the results. We first show that there are no significant pre-trends in investment or financial policies before the loss events between the firms that experience a loss of exclusivity and control firms. To further ensure that the negative effect on revenues and cash flows is not somehow spuriously driven by our methodology for collecting patent information, we also consider the expiration of "non-critical" patents as a "placebo" robustness test. We define non-critical patents as those that expire but that are not followed by generic entry. We find that the expiration of non-critical patents is not associated with a statistically significant impact on firm revenues, and consequently, also is not associated with cuts to investment. We similarly separately study the impact of the loss of exclusivity for economically less important drugs - defined as those that represent less than $1 \%$ of firm revenues before the loss - and find little measured impact on any of our outcome variables.

These results provide important evidence of how generic entry impacts future innovation (e.g., Branstetter, Chatterjee, and Higgins (2014); Murphy (2017)). Crucially, this evidence is broadly consistent with the view that revenue from existing branded products are used to support subsequent innovation. However, our evidence does not allow us to assess whether this subsequent innovation would be socially optimal (Branstetter et al. (2016)). Importantly, our findings also suggest that firms are practically failing to effectively plan across their pipeline and product lifecycles. ${ }^{5}$

Overall, these results point to assets in place as having a vital role in firm decisions. First, expenditures on investment opportunities, as measured by investment and R\&D, are strongly related to the loss of market exclusivity for branded drugs, particularly those that generate a large share of the firm's revenue. Second, the timing of these expenditures on investment

\footnotetext{
${ }^{5}$ This does not mean they are not trying (e.g., Amoresano (2007); Prajapati and Dureja (2012)). However, these efforts do not appear to be sufficiently effective. For example, Pfizer's efforts to develop a follow-on or next-generation drug for their global blockbuster, Lipitor, ultimately failed.
} 
opportunities is not strongly related to raising funds from equity. Critically, these findings contradict the main predictions of traditional capital budgeting explanations. Instead, this evidence suggests that costly external financing affects firms' decisions in a manner that is more consistent with the pecking order theory.

The paper is organized in the following manner. Section 2 provides an overview of the setting and regulatory environment, describes the loss of market exclusivity events, and explains how this information is linked to data about firms' investment and financing decisions. Section 3 describes the empirical strategy. Section 4 documents the substantial negative impact of the loss of market exclusivity on firm revenue and profitability. This section also analyzes the relation between the loss of market exclusivity and the investments in R\&D and capital expenditures, payouts, cash holdings, and external financing. Section 5 describes cross-sectional evidence regarding the role of financial constraints, and Section 6 discusses robustness tests. We conclude in Section 7.

\section{Data}

\section{$2.1 \quad$ Regulatory environment}

The current regulatory environment faced by pharmaceutical companies in the United States can be traced to the passage of the Drug Price Competition and Patent Term Restoration Act in 1984, informally known as the "Hatch-Waxman" Act. The Act provided a delicate balance between expedited FDA approval for generic entry and extensions to pharmaceutical patents in order to compensate innovators for lost time while waiting for FDA approval (Grabowski and Kyle (2007)). ${ }^{6}$ When a pharmaceutical company submits a New Drug Application (NDA) to the FDA for approval they are required, by law, to identify all relevant patented

\footnotetext{
${ }^{6}$ There are limits to such extensions. Pharmaceutical firms cannot receive a patent extension of more than five years, nor are they entitled to patent extensions that provide them with a patent life (post-approval) that is effectively greater than 14 years.
} 
technologies necessary to create the drug; these patents are subsequently listed in the FDA Orange Book. ${ }^{7}$

Upon approval, the FDA will grant each new drug regulatory protection lasting for five years (also known as data exclusivity) which runs concurrently with patent protection. ${ }^{8}$ During this data exclusivity period, regardless of the status of the underlying patent(s), no generic entry may occur. At the conclusion of data exclusivity, branded products are protected only by their patents; this period running from the cessation of data exclusivity to the expiration of the patent(s) is commonly referred to as "market exclusivity" (see Appendix Figure 1).

Prior to the passage of Hatch-Waxman, generic manufacturers seeking to enter the market had to demonstrate the safety and efficacy of their products by putting them through clinical trials (Mossinghoff (1999)). While Hatch-Waxman did not lessen the burden of the clinical trials process for branded pharmaceutical companies seeking approval for new drugs, it virtually eliminated the requirement for separate clinical trials for generic manufacturers. This was made possible since generic manufacturers could simply demonstrate "bioequivalence" with branded products by showing that the active ingredient in their product diffused into the human bloodstream in a manner similar to the original product.

Hatch-Waxman provides four pathways (or "Paragraphs") a generic firm may follow in order to gain entry into a market. The process starts with filing an Abbreviated New Drug Application by a generic manufacturer with one of the four Paragraph certifications. A Paragraph I certification is one for which the originator firm has not filed patent information for its branded product. Paragraph II certification relates to when the branded product's patent has already expired (i.e., the end of market exclusivity), and Paragraph III certification re-

\footnotetext{
${ }^{7}$ Importantly, outside of the requirement to list relevant patents, there is no regulatory screening of which patents firms ultimately choose to list in the Orange Book. This has led to criticism of gaming in terms of when patents get listed (Bulow (2004)) and the relevance of the patents themselves (Hemphill and Sampat (2011); Hemphill and Sampat (2012)). The implication of this regulatory anomaly is that not every patent attached to a branded drug will allow for generic entry upon the patent expiring. We use this anomaly as a basis for one of our placebo tests.

${ }^{8}$ Orphan drugs receive seven years of data exclusivity, reformulations receive three years of data exclusivity, and pediatric indications receive an additional six months of data exclusivity.
} 
lates to cases when the generic manufacturer notes that the patent on the branded product will expire on a specific date and that it seeks to enter only after patent expiry or end of market exclusivity. Paragraph IV, the fourth certification, argues that the generic manufacturer does not infringe on a branded product's patents or that those patents are invalid. More importantly, however, a Paragraph IV certification can be acted on by the FDA after the conclusion of data exclusivity anytime during the market exclusivity window (see Appendix Figure 1). ${ }^{9}$ These certifications result in litigation, and in the case that the challengers are successful, this would bring generics to the market earlier than otherwise would be the case (Higgins and Graham (2009); Grabowski and Kyle (2007); Panattoni (2011); Palermo et al. (2019)).

It is critical to note that the preceding discussion relates only to chemical-based or smallmolecule drugs. Generic versions of biologic-based drugs (often referred to as biosimilars) are governed by the Biologics Products Competition and Innovation Act, which was passed in 2009. However, due to a delay in the enabling regulations, the first biosimilar was not introduced in the U.S. until 2015. As we discuss below, this will be outside of our sample period. For this paper's purposes, our focus will be on the loss of market exclusivity and subsequent generic entry surrounding chemical-based or small-molecule drugs.

\subsection{Sample of branded drugs}

Our sample begins by creating a sample of loss-of-exclusivity events between 1999 and 2016 for drugs that have significant sales. To do so, we first collect revenue information on branded drugs in the U.S. market. Our main source for this data is the IMS MIDAS (now IQVIA) database. This is a quite comprehensive database of quarterly drug sales, and our sales data covers the years 1998-2010. We use several additional resources to build out our list

\footnotetext{
${ }^{9}$ Paragraph I and II certifications are rarely used. Paragraph III certifications are the most common filing by generic firms because they will be anticipating the expiration of underlying patents (Federal Trade Commission (2002)). Paragraph IV challenges have increased over time, especially since 2003; however, this mode of entry is still probabilistic as it depends on a litigation outcome (Berndt, Danzon, and Kruse (2007); Palermo, Higgins, and Ceccagnoli (2019)). For reasons we discuss below, we will focus on generic entry via Paragraph III certifications.
} 
and to ensure that our data covers as many of the highest-revenue drugs as possible. These additional data sources consist of lists from two pharmaceutical magazines, Drug Topics and Medical Advertising News, which publish lists of either Top-100 or Top-200 branded drugs by sales, and the online website drugs.com. In general, these high-revenue drugs or 'blockbusters' tend to persist over time.

Next, we hand-collect the expiration dates for all the patents attached to these drugs from the FDA Orange Book. This dataset contains detailed information on approved drugs, including the name of applicants, active ingredients, availability of generic counterparts, and each patent's expiration date. Firms will frequently get regulatory extensions for their patents, for example, due to the time spent in the FDA approval process. To ensure that the patent expiration dates that we identify include any granted extensions, we augment our data using the extended patent information as published by the United States Patent and Trademark Office.

Next, we take these patent expiration dates, including their extensions, and look for introductions of generic drugs entering within six months of a patent expiration. This merge between patent expiration dates that are followed by generic entry forms our main set of loss of market exclusivity events. We use the IMS MIDAS data to measure revenue during specifically in the quarter preceding patent expiration; for dugs with patents that expire after 2010 when our IMS MIDAS data ends, we use the last available sales data. The branded drug's revenue before expiration is used to determine if the patent's expiration is likely to have a meaningful impact on the firm. Even if a drug has substantial sales, it can still be a small portion of overall revenues for the largest pharmaceutical firms. Because our IMS data starts in 1998, this data requirement narrows the list of drugs to those with patents that expire after this date.

Merging the patent expiration dates and generic entry dates has two purposes. First, we seek to eliminate generic entry that is not associated with loss of market exclusivity (i.e., those that are not Paragraph III generic entry). In these cases, the entry may be unantici- 
pated, or at least probabilistic (Lemley and Shapiro (2005)). For example, as discussed in the prior section, a firm's monopoly position can be lost before losing market exclusivity if a branded firm loses an early generic "Paragraph I" challenge (Palermo et al. (2019)). By contrast, if a generic enters because of the loss of market exclusivity (i.e., Paragraph III generic entry), then that event can be fully anticipated.

Second, we also exclude patent expirations that are not followed by generic entry. One plausible explanation why this may occur, as noted previously, is that not every patent listed in the FDA Orange Book will allow for generic entry upon expiration. These "non-critical" patents will become the basis of one of our placebo tests, but they are excluded from our main specifications because there is no resulting shock to a firm's cash flow. In total, we identify 410 branded drugs with patent expiration information data, and that are associated with generic entry. ${ }^{10}$

\subsection{Merging loss of market exclusivity events to firm-level vari- ables}

We next manually match the owner of each branded drug to company identifiers in Compustat North America. We require a company to be covered by Compustat to obtain standardized accounting information; this requirement nevertheless results in excluding pharmaceutical firms that are based abroad. When a firm's subsidiary owns the branded drug, we identify its parent firm in Compustat. We specifically identify the owner as of the patent expiration date, and this owner may not be the original patent holder. For example, owners of branded drugs can change due to several reasons such as licensing, mergers and acquisitions, corporate spin-offs, or sales of the individual drug. Overall, the sample period from

\footnotetext{
${ }^{10}$ As we noted in Footnote 8, while there is a patent reporting requirement, there is no formal screening mechanism for which patents get listed in the FDA Orange Book. As a result, firms may have an incentive "over-list" patents. Moreover, not every patent will cover a drug's entirety, so its expiration should not be expected to allow for entry.
} 
Compustat ranges from 1996 to 2017, so as to include data both in the period before the first loss-of-exclusivity event and after the last event.

Next, we apply a few filters to our data. First, we drop firms from the sample if R\&D or revenues are zero or missing. This is to ensure we have data to measure the impact on $\mathrm{R} \& \mathrm{D}$, and to remove firms whose main role may be purely marketing. Second, we remove firms if their quarterly C.P.I.-adjusted assets or quarterly revenues are smaller than $\$ 1$ billion or $\$ 100$ million, respectively. Third, we exclude firms if their age is younger than 15 years. These latter two filters only remove one loss-of-exclusivity event from our sample; however, this filter is crucial as the purpose of the study is to determine the impact of the loss of market exclusivity for the affected firms, as compared to a control group of firms that do not experience such a loss. It is, therefore, important to filter on the firm's age to ensure that we are comparing established companies with similar peers as control firms, and we correspondingly apply a symmetric filter to our "control" firms. If we did not impose these filters, the firms experiencing a loss of market exclusivity would almost by construction be older and larger than the control firms, which in turn could shed doubt on the parallel trends assumption that is necessary for an interpretation of plausibly causal effects in the difference-in-differences framework.

This procedure yields 115 loss-of-exclusivity events for our sample period that are matched to Compustat firms and meet the above filters. ${ }^{11}$ Table 1 lists the 25 drugs with the largest sales during the quarter before the loss of market exclusivity in our sample. Many of these brands and the associated firms are widely recognized even outside the medical field.

To measure these events' predicted impact, we use the IMS MIDAS data to measure a drug's sales before the loss of exclusivity, scaled by the firm's total revenue. Even if a drug has substantial sales, it can still be a small portion of overall revenues for one of the largest pharmaceutical firms. We will use a sample of such "small impact" events for a placebo-type robustness test.

\footnotetext{
${ }^{11}$ In a few instances, a firm experiences several loss-of-exclusivity events within the same quarter; in these cases, we sum the revenues of the drugs to estimate the impact of the event.
} 


\subsection{Drug-level cash flow patterns around the loss of market ex- clusivity}

To illustrate the impact the loss of market exclusivity can have, consider the example of Lipitor, which is marketed by Pfizer. In our sample, Lipitor had the highest revenue before the loss of market exclusivity (see Table 1). It also had the highest annual revenue in the U.S. of all drugs from 2003 to 2009 and was the second-highest revenue drug in 2010. In November 2011, the patent for Lipitor expired. Figure 1 shows the revenue pattern from Lipitor around the date of the loss of market exclusivity. The event is represented by the vertical line in the middle of the figure. As reported, quarterly global revenues were approximately $\$ 2.5$ billion for the quarter before the loss of market exclusivity. Following the loss of market exclusivity, quarterly revenues decreased to less than $\$ 1$ billion within four quarters and continued to fall by another 30 percent the following year. In the two years following the loss of market exclusivity, the annual revenues generated from Lipitor declined by approximately $\$ 8$ billion.

Unsurprisingly, this significant change in revenue for Lipitor also had a substantial impact on Pfizer's total revenue. Pfizer's 2011 revenues were approximately $\$ 65$ billion, declining to approximately $\$ 55$ billion in 2012 and continuing to decline in 2013. Such a significant revenue decrease also affected Pfizer's profitability and cash flow metrics. Importantly, this decrease in revenue was nevertheless "predetermined" by many years based on the patents protecting the drug, which makes the loss of market exclusivity event predictable long in advance, and the loss-of-exclusivity event by itself contained little information about the NPV of Pfizer's other drugs in development and the potential of future research.

In Figure 2, we use all drugs in our sample to study the average change in drug revenues around the loss of market exclusivity. This figure plots the average fraction of revenues for each drug relative to that drug's maximum quarterly revenues in our sample period in event time (quarters) around the quarter when the loss of exclusivity took place. This quarter 
$(t=0)$ is represented by the vertical line. Scaling by maximum quarterly revenues for each drug is designed to standardize the magnitude of the decline across drugs.

The pattern for this average of scaled revenues around the end of market exclusivity across all drugs in our sample is roughly similar to the pattern we saw for Lipitor in Figure 1. This pattern is also consistent with the extant literature (e.g., Branstetter et al. (2016); IMS Institute for Healthcare Informatics (2016); Reiffen and Ward (2005)). Average revenues decline by more than $80 \%$ within the two first years after the loss of market exclusivity. Specifically, the graph shows that sales decrease from approximately 80 percent of a drug's maximum sales from the quarter before losing market exclusivity to less than 15 percent of the maximum sales within two years of losing market exclusivity.

Even though generic entry after the loss of market exclusivity occurs relatively quickly, the graph shows that the full impact on the branded drug's revenues does not take place immediately. ${ }^{12}$ For example, it may take time for consumers to renew a prescription, at which time state substitution laws would transition the consumer, in most cases, to a generic. Branded drug companies can also seek to moderate the decline, for example, by distributing discount cards to consumers, subsidizing co-pays, and other kinds of rebates to try to extend branded usage.

Nevertheless, based on this figure, most of the decline in revenues due to the loss of market exclusivity occurs within the first year. ${ }^{13}$ To ensure that our results are not spuriously affected by such mitigating actions a firm may take, our identification will crucially not use the actual sales decline after a loss of exclusivity event; instead, we will only exploit variation in the predicted sales decline based on each drug's pre-loss-of-exclusivity sales.

\footnotetext{
${ }^{12}$ This revenue decrease is driven by lower quantities. By contrast, branded drug prices often tend to increase as firms are exploiting the relatively more price inelastic consumers that remain on branded drugs even in the presence of generic drugs (Frank and Salkever, 1997).

${ }^{13}$ There remains the nuance of different dosages. For example, suppose a drug is sold in $30 \mathrm{mg}$ and $60 \mathrm{mg}$ forms. Generic entry is form specific; for example, suppose it only applies to the $60 \mathrm{mg}$ tablet. If a consumer took the $60 \mathrm{mg}$ tablet, they would get the $60 \mathrm{mg}$ generic because of state substitution laws. However, their doctor could prescribe twice the amount of $30 \mathrm{mg}$ pill, in which case they would get the $30 \mathrm{mg}$ branded pills. Our revenue data are at the brand-level, not the dosage level, so some of the slower dissipation could be due to the existence of multiple dosages and the rates at which generics come online for additional dosages.
} 
As firms know about this expected decrease in revenues resulting from the loss of market exclusivity well before the actual expiration date, we can use this predetermined event to analyze how critical corporate decisions are affected by the change in cash flows from these "assets in place." In the next section, we consider these effects in the context of pharmaceutical firms experiencing the loss of market exclusivity in terms of their policies regarding investment, R\&D, payout, and external financing.

\section{Empirical strategy and identification}

Our baseline empirical strategy compares firm-level outcomes between firms that experience a loss of market exclusivity ("treated" firms), compared to a control set of peer firms that do not experience such a loss over the same period. The underlying identification assumption is that the treated firms would have behaved similarly to the control firms in the absence of having experienced the loss of market exclusivity event.

To ensure comparability between the treated firms and the control firms, we follow the approach in Gormley and Matsa (2011) to construct cohorts of peer firms. A cohort consists of all 'treated' and 'control' firms as of a specific calendar quarter. We form such cohorts around every calendar quarter, in which at least one firm experiences a loss of market exclusivity event. Around each quarter with such an event, we create groups of treated firms (those that experience a loss) and control firms (those that do not experience a loss around the same time), and analyze these firms in event time around the focal quarter where the event for the treated firms takes place. For example, suppose two firms lose market exclusivity in Q1:2002, which we refer to as the "event quarter" $(t=0)$ for the cohort of Q1:2002. Then those two firms are the treated firms of that cohort, and we additionally form a set of control firms for that cohort drawing from other pharmaceutical firms that do not experience loss of market exclusivity in that event quarter. Our analysis then compares how these two groups of treated and control firms in the same cohort behave in event time over eight 
quarters before $(t-8)$ to eight quarters after $(t+8)$ the event quarter. We form similar groups of treated and control firms around every other calendar quarter with at least one loss-of-market-exclusivity event.

To construct the set of firms within each cohort, we start with all firms in the pharmaceutical SIC industry classification $(S I C=2834)$. As we described in the previous section, we apply a set of data filters to the treated firms based on their size, age, and R\&D activities, to ensure that these are established pharmaceutical firms that are active in R\&D. To ensure comparability, we, therefore, apply symmetric filters to the set of control firms. Specifically, from the set of possible control firms within the pharmaceutical sector, we drop firms that have $R \& D$ expenses that are missing or zero, or that have revenues that are missing or zero. We exclude firms with C.P.I-adjusted assets or quarterly revenues that are smaller than $\$ 1$ billion or $\$ 100$ million, respectively, and firms with age younger than 15 years (all characteristics are measured as of the focal quarter). The purpose of these filters is to ensure that the activities of established pharmaceuticals experiencing the loss of market exclusivity are compared to similar peer firms that might be expected to display similar trends over time in the absence of treatment. For example, we would not want to compare established pharmaceutical firms to biotechnology start-ups; the latter firms could have patterns of investment that are quite different, even absent any loss-of-exclusivity events. We validate that this methodology produces similar "pre-trends" between the treated and control firms, which supports the parallel trends assumption.

After pooling all event-time cohorts, we estimate the impact of the loss of market exclusivity on revenue for the treated firms as follows:

$$
y_{i, q, c}=\beta_{0}+\beta_{1} \operatorname{Loss}_{i, c}+\beta_{2} \text { Post }_{q, c}+\beta_{3} \text { Loss }_{i, c} \times \text { Post }_{q, c}+\gamma_{i, c}+\omega_{c, q}+\epsilon_{i, q, c}
$$

In Equation (1), $y_{i, q, c}$ is the dependent variable for firm $i$ in event time $q$ and cohort c. The outcome variables we study include the effects on firm revenues, profitability, R\&D, 
capital expenditures, payouts (dividends and repurchases), equity issuance, debt issuance, and cash.

Loss is an indicator for whether the firm $i$ in cohort $c$ is treated, i.e., whether it experiences a loss of market exclusivity event in the focal quarter. Post is an indicator variable for whether event quarter $q$ is in the post-event period for cohort $c$, i.e., within the eight quarters after the loss-of-exclusivity. The main coefficient of interest is $\beta_{3}$, which measures how the treated firms alter their behavior after the loss of market exclusivity compared to control firms.

The variable $\gamma_{i, c}$ in Equation (1) represents firm-cohort fixed effects, and $\omega_{c, q}$ represents event-time-by-cohort fixed effects. The firm-cohort fixed effects control for any unobservable firm-level characteristics that are time-invariant around the event; these characteristics are only assumed to be constant within a cohort, and we allow them to vary for the same firm across cohorts that represent different event quarters. The event-time-by-cohort fixed effects control for any aggregate (e.g., macro- or industry-level effects) that affect all firms in the same cohort over time. These two groups of fixed effects subsume the coefficients on $\beta_{1}$ for Loss and $\beta_{2}$ for Post, respectively. We cluster the standard errors across two separate dimensions, at the firm level, and at the time (calendar-quarter) level.

This analysis could be confounded if the control firms were to experience a loss of market exclusivity at some time that is 'close' to the event quarter, in which case they would also effectively be treated for many of the quarters in the eight-quarter window around the focal quarter. This, in turn, would have the effect of biasing down the measured impact of any actual events. For example, suppose that the focal event quarter is Q1:2002, and that a potential "control" firm did not experience a loss in that quarter, but did experience such a loss of market exclusivity in the next quarter (Q2:2002). If this firm were included as a control firm within the Q1:2002 focal quarter cohort, it would distort any difference between the treated and control firms, since the control firm also lost significant revenues during the post-period. To mitigate this concern, we remove control firms from the cohort if they also 
experience any loss-of-exclusivity events within the time window between quarter $t-8$ to $t+8$.

Occasionally, the same treated firm can also have multiple events within a short period. If a firm has two events within 16 quarters of each other, which would result in overlapping observations for the same treated firm, then the event for the drug that has the most significant impact on firm revenue is included, while the event with the smaller impact is removed. This firm is also excluded from being a control firm around the event quarter associated with the loss of market exclusivity for the smaller-revenue drug. ${ }^{14}$ For example, suppose the same firm has an event in Q1:2002 and in Q4:2002, but the Q1:2002 event is more significant. Then we remove this firm from the cohort of Q4:2002 (i.e., it is included neither as a treated firm nor as a control firm in that quarter), and further, it is not a control firm in any cohort that lies within eight quarters after the latter event or within eight quarters before the earlier event.

Table 2 presents summary statistics for our panel of treated and control firms between 1996 and 2017. The distribution of book assets and firm revenue indicates that these firms tend to be larger and more profitable than the typical firm in Compustat. This table also reports the average value for several asset-scaled outcome variables that we will examine, including revenues, net income, capital expenditures, R\&D, dividends, repurchases, equity issuance, debt issuance, and cash. All variables are defined in Table A.1 in the Appendix. In general, the typical firm in our sample has substantial R\&D expenditures, holds large cash balances, and is highly profitable.

\footnotetext{
${ }^{14}$ This filter reduces the number of events from 115 to 55; however, the dropped observations represent the smaller and thus less significant events by construction.
} 


\section{Results}

\subsection{Pre-trends analysis}

Before turning to our primary analysis, we first investigate whether there are any pre-trends before the loss of market exclusivity that could have the potential to contaminate the main

results. In Panel A of Table 3, we regress the average quarterly changes for all of our outcome variables from $t-4$ to $t-1$ on the indicator for loss of market exclusivity (LossOfExclusivity) followed by generic entry for the firm in quarter $t$. This indicator variable is not statistically significant in any of the regressions in Panel A. Crucially, this result shows that there are no differences in trends across any of these variables before the loss of market exclusivity between the treated and control firms.

The finding of no differential trends, particularly in the financial policies, is particularly noteworthy in this setting. This result implies that the treated firms do not seem to prepare before the loss of market exclusivity in ways that can soften the impact of the loss-ofexclusivity event. For example, the treated firms could have increased their cash reserves before the loss of market exclusivity to ensure a buffer to weather the predictable negative shock to revenues; but our findings suggest that they did not substantially do so.

\subsection{Effects on revenues and profitability}

Next, we estimate the impact of the loss of market exclusivity on revenues and profitability. These results are reported in Table 4 . In Model 1, we find that revenue scaled by lagged assets is significantly lower. Quarterly revenue scaled by assets is 3.3 percentage points lower during each quarter on average during the eight quarters following the loss of market exclusivity events for the treated firms as compared to the control firms. Critically, this means that scaled revenue declines by approximately 20 percent compared to its unconditional average of $16.8 \%$ (as reported in Table 2). In Model 2, we examine the analogous specification for 
net income scaled by lagged assets. While the coefficient estimate is negative, the results are not significant for the full sample.

However, this test about the impact of the loss of market exclusivity may be of limited statistical power because some of the drugs in our sample may represent only a small share of a firm's total revenue. Even though revenues for a specific drug may decline, the overall impact could be limited at the firm level if the drug represents only a small part of its total business. To address this concern, we consider a more restrictive set of loss of market exclusivity events. As in Table 3, we define an indicator as a loss of market exclusivity event for a drug that generates more than 1 percent of the firm's total revenues.

In Models 3 and 4, we show that focusing on these events, which excludes the relatively less economically important events, further increases the coefficient estimates compared to the results for the full sample of events (Models 1 and 2). The magnitude of the relevant coefficient increases by about 20 percent for the revenue specification (Model 3) and remains strongly significant, and the coefficient estimate more than doubles for the net income specification (Model 4) and is also statistically significant. The estimated coefficient in Model 4 suggests that net income declines by approximately 30 percent, on average, relative to the unconditional mean in Table 1 during the eight quarters following the loss of market exclusivity around these economically more important events.

Collectively, these results on revenues and net incomes are not very surprising insofar as when a drug loses market exclusivity, we would naturally expect a firm's revenues and net income to drop. However, this table provides a sense of the magnitude of the "first stage", that is, how large this drop is in economic terms. Moreover, this drop illustrates how challenging lifecycle management is in the pharmaceutical industry. We can now turn to comparing these magnitudes to the actions that firms take following these events in terms of their investment and financial policies, which we analyze in the next subsections. 


\subsection{Effects on R\&D and investment policies}

In Table 5, we estimate the impact of the loss of market exclusivity on firms' investment decisions. We use Equation (1) with the following dependent variables: (1) capital expenditures (CapEx) scaled by lagged assets, (2) research and development expenditures (R\&D) scaled by lagged assets, and (3) the sum of these two variables, which we label investment.

First, we find that the impact of the loss of market exclusivity on capital expenditures by itself is not statistically significant (Model 1). However, critically, we find a large and negative effect on $R \& D$ (Model 2) around these events. The coefficient estimate indicates that R\&D spending declines by 0.6 percentage points (scaled by lagged assets). Compared to the baseline level of R\&D spending of 2.4 percent of lagged assets in Table 2, this change implies roughly a 25 percent reduction in $\mathrm{R} \& \mathrm{D}$ spending. The third measure, total investment (Model 3), represents the sum of capital expenditures and R\&D, and also displays a significantly negative effect after losses of market exclusivity.

In Models 4-6, we revisit this relation using the more restrictive set of loss of market exclusivity events for drugs generating more than 1 percent of firm revenue. We find the same statistical pattern for all three specifications, although the economic effects are now generally larger; this is expected as these events are, on average, more important in economic terms. These findings show that losing market exclusivity for an already-existing drug has a negative effect on spending in support of long-term investment opportunities.

This key result illustrates an essential role that revenues from assets in place have in terms of supporting investments in $\mathrm{R} \& \mathrm{D}$. The fact that we find relatively stronger effects for $R \& D$ compared to capital expenditures is not particularly surprising because $R \& D$ is a much larger and more volatile component of spending compared to capital expenditures among the pharmaceutical firms in our sample. These differences between capital expenditures and R\&D may also be driven by the differences in the horizon until cash flows from these different types of projects materialize. While building a plant to manufacture a drug that has already 
been approved could be considered a late-stage investment that will generate cash flow in the near term, cutting R\&D, by contrast, implies cutting the search for new opportunities that will only affect cash flows in the more distant future.

\subsection{Effects on financial policies}

Table 6 shows how firms adjust payout policies when they experience a loss of market exclusivity. The outcome variables include dividends (Model 1), repurchases (Model 2), and total payout (Model 3), where the total payout is the sum of dividends and repurchases. As before, all of these variables are scaled by lagged total assets. ${ }^{15}$ We exclude the economically less important events, and focus only on those drugs that represent at least $1 \%$ of firm revenues. ${ }^{16}$

Somewhat surprisingly, we find that dividends tend to slightly increase following these events, despite lower revenues and income. ${ }^{17}$ On the other hand, we find that firms drastically cut repurchases. This cut to repurchases is larger in total economic terms than the increase in dividends, resulting in lower total payouts (as shown in Model 3).

In Table 7, we next study how firms adjust their issuance of equity and debt securities (Models 1-2), and the effect on cash balances (Model 3). One possible way for firms to buffer any shock to investment would be to increase their use of external financing by issuing new equity or debt. However, in Models 1 and 2, we do not find any statistically significant responses regarding either increased equity or debt issuance.

Firms could also seek to buffer some of the impacts on investment by saving less cash or spending more of their internal stock of cash holdings. We test this in Model 3 of Table 7 and find a negative and statistically significant response whereby the affected firms are significantly spending down their cash relative to the control firms. This effect is substantial

\footnotetext{
${ }^{15}$ Our measure of share repurchases scaled by assets is defined as zero if the net of stock repurchases minus sales is negative. We also study equity issuance separately in Table 7.

${ }^{16}$ Results using all events are similar, but not tabulated for brevity.

${ }^{17}$ In untabulated results, we find that the positive effect on dividends mainly tends to be larger among the observations that represent a relatively smaller loss of market exclusivity, where it is plausible that firms might be increasing dividends as a signal that they remain stable even in the presence of this shock.
} 
in magnitude and shows that firms draw down their existing cash balances when faced with a loss of market exclusivity. However, the previous results on lower R\&D nevertheless show that these reductions in both cash balances and share buybacks are not sufficient to buffer the decline in investments fully.

\section{The role of financial constraints}

To the extent that financing frictions, i.e., costly external financing, drive the effects on investment, we would expect these effects to be larger for firms that are more likely to be subject to such frictions and thus less able to substitute the loss of internal cash flows with other sources of financing. We explore this hypothesis in Table 8.

Our proxy for the lack of financing frictions,(Unconstrained) is whether a firm is among the Top-10 percent of firms in terms of revenues within the Compustat universe, which roughly corresponds with the set of S\&P500 firms. We choose this proxy based on the literature, which has established that smaller firms tend to be relatively more financially constrained in having worse access to external financing than large firms (e.g., Hadlock and Pierce (2010)). Other possible proxies for financing constraints that exist in the literature tend to yield little cross-sectional variation within our sample; for example, virtually all of the firms in our sample have investment-grade credit ratings, which is another commonly used proxy (e.g., Campello, Graham, and Harvey, 2010). Similarly, firm age is a common proxy for financial constraints that also yields little variation in our sample, as we require both the treated and control firms to be at least 15 years old.

To study the cross-sectional differences in these effects, we expand Equation (1) to include a triple-difference with Unconstrained. ${ }^{18}$ The first two models of Table 8 focus on firm investment policies while the remaining models focus on financial policies (payout, issuance,

\footnotetext{
${ }^{18}$ Note that the Unconstrained variable itself and the double-interaction Unconstrained ${ }^{*}$ Loss are absorbed by the Firm*Cohort fixed effects; as before, Post and Loss are absorbed by the EventQuarter*Cohort and Firm*Cohort fixed effects, respectively.
} 
and cash). This table also focuses on the events for the losses of market exclusivity that represent more than 1 percent of the firm's revenues.

Models (1) and (2) suggest that the effects on R\&D and total investment are significantly larger for the smaller, and thus more financially constrained firms, while the coefficient on the triple interaction shows that the effect for larger firms is significantly attenuated. For example, the effect on R\&D for smaller firms is -1.795 percent, but only $-1.795+1.271=$ -0.524 for the largest firms. These results suggest that the largest firms can better buffer investment effects from the adverse cash flow shocks.

There are also differences across these groups regarding how they adjust their payout and issuance policies. In Model 3, we see that the dividend increases we found in the previous section is an effect that is limited to only the larger firms. This result suggests that our prior finding on dividends (shown in Model 1 from Table 6) appears to be driven by larger firms, whereas we do not observe any dividend increases on average among smaller firms around these events.

On the other hand, the relatively smaller firms are decreasing their equity issuance more (Model 6) and significantly increasing their debt issuances more (Model 7) than larger firms. By contrast, large firms do not change their issuance after these events. Finally, smaller firms tend to draw down more of their cash than larger firms (Model 8).

Overall, the results in Table 8 are consistent with a pecking-order hypothesis. Treated firms suffer a large negative shock to internal cash flows. This is followed by adjustments across multiple margins, including investment, payout, external financing, and internal cash policies. Crucially, the adjustments in terms of payout, external financing, and internal cash, when taken together, are still insufficient to buffer the shock to investment policies, which a baseline model of capital budgeting would predict should be unaffected. Importantly, the only exception is among larger firms that tend to be less financially constrained, and these firms also appear to be better able to isolate their investments in R\&D from these negative shocks due to losses of market exclusively. 


\section{Robustness tests}

To supply additional support for our identification strategy, we run a series of placebo tests in Tables 9 and 10 .

The first placebo test in Table 9 considers the impact of patent expirations that are not followed by generic entry (we call these "non-critical patents"). As discussed earlier, firms must list relevant patents for an approved drug in the FDA Orange Book. Given that these patents are not formally screened, patents of marginal value sometimes get listed (Bulow (2004); Hemphill and Sampat $(2011,2012)$ ). The net effect of this regulatory anomaly is that the expiration of some of the patents attached to an approved drug will not result in generic entry (i.e., the loss of market exclusivity).

In Table 9, we begin by redefining the event indicator to consider the impact of the expiration of a (non-critical) patent that is not followed by generic entry. In the absence of generic entry, the impact of these events on all aspects of firm performance that we have discussed previously should be negligible. We find this in Model 1, where the estimated coefficient on revenue is not statistically significant. Likewise, we find the same in Model 2 ; the effect on profitability is not statistically significant. These findings suggest that the procedures for identifying the timing of patent expiration and loss of market exclusivity do not artificially generate the statistically significant decline in revenue and profitability observed in Table 4.

Proceeding to the remaining models in Table 9, we find no significant relation between the expiration of a non-critical patent and most of the variables measuring the effects on firms' investment and financing decisions. The results in Models 3 and 4 are particularly important. The relation between R\&D (Model 3) and investments (Model 4) and non-critical patent expiration without generic entry are both not statistically significant. This makes us more confident in the significant impacts we previously found because of the loss of market exclusively on R\&D (Table 5, Model 5) and investments (Table 5, Model 6). Similarly, the 
effects for share repurchases, total payout, or cash holdings are not statistically significant and again provide additional confidence in our main findings. On the other hand, the significant result for dividends suggests that the positive and statistically significant result in Table 6 should be interpreted with some caution.

In Table 10, we employ a second placebo test that considers small-market drugs or those for which a loss of market exclusivity event should have negligible effects on the focal firm. The sample of placebo events is defined by the loss of market exclusivity for a drug that generates less than 1 percent of firm revenue. For these events, we should thus not observe substantial investment effects for the focal firms, or at least not large effects as these drugs are quite small as a fraction of firm revenues, which means that firms should be able to buffer these shocks internally. Except for Model 7 that estimates the impact on cash holdings, the coefficient estimates are not statistically significant.

In sum, these placebo results in Table 9 and Table 10 provide further support for our identification strategy and core findings.

\section{Conclusion}

The expiration of a pharmaceutical drug's patent protection and the resulting loss of market exclusivity can substantially negatively impact a drug maker's revenues and profitability. However, because the timing of this change in the firm's cash flows is predetermined more than a decade in advance, the event itself is predictable and contains little news about the profitability of the firm's future projects. The traditional capital budgeting theory would thus suggest that a firm's fundamental decisions about the long-term investment, such as R\&D spending, would be unrelated to this event.

Our results are inconsistent with this fundamental prediction of traditional capital budgeting. We show that pharmaceutical firms' R\&D declines by approximately 25 percent during the eight quarters when their previous high-revenue drugs lose market exclusivity. 
Total investment, defined as the sum of capital expenditures and $R \& D$ spending, is also significantly lower during the quarters following these events.

Firms' financing decisions also indicate that firms employ other margins of adjustment. We find that firms do significantly fewer share buybacks after these events and also consume their stock of cash holdings. However, these actions appear to be insufficient in terms of buffering the effect on investment. An exception is for the largest pharmaceutical firms in the sample, which tend to be less financially constrained, and that also maintain their investments in $R \& D$ at the same rate after these events. On average, debt issuances and equity issuances do not change. Our paper speaks to the crucial role that a firm's existing cash flows have for the development of future products, even when reductions in those cash flows contain no news about the profitability of those future cash flows.

We focused on chemical-based or small molecule drugs. This restriction was made because generic biologics or "biosimilars" were not present during our sample period; the first biosimilar was not approved in the U.S. market until 2015. There are important distinctions between these drugs and the chemical-based or small molecules drugs we considered in this paper. First, biologic-based drugs receive 12 years of data exclusivity, as opposed to five years for most chemical-based drugs. ${ }^{19}$ Importantly, the process that biosimilars take to get approved is different from generics for chemical-based drugs. There is no equivalent Paragraph IV pathway for biosimilars, so their only route of entry is equivalent to Paragraph III entry or waiting until the loss of market exclusivity. Because of their nature, biosimilars are required to undergo limited clinical testing, which dramatically increases their cost to develop and limits the kinds of firms that can engage in this activity.

Longer European experience with biosimilars (Morton, Stern, and Stern, 2018) suggests that entry is much less frequent, occurs at a later point in the product lifecycle, and offers a much smaller price discount relative to the innovator drug than has been the case for generic entry in chemistry-based drug markets. This implies that the revenue shock that we

\footnotetext{
${ }^{19}$ The section of the Affordable Care Act that details entry provisions for biologics is referred to as the Biologics Products Competition and Innovation Act (BPCIA).
} 
find in this paper, related to chemical-based drugs, may not be as stark or significant with biologic-based drugs. This could create yet another incentive for pharmaceutical firms to begin to rotate their focus from chemical- to biologic-based drugs (Branstetter et al., 2014). While we are unable to comment on the welfare implications of such a shift, we can say that it would alter the nature of innovation and dramatically increase the future cost of drugs given their significant price differences.

Finally, our work has significant implications for product lifecycle management. The pharmaceutical industry is unique in that it has such a long development product lifecycle. This should, theoretically, provide ample opportunity for firms to plan for these loss-ofmarket-exclusivity events. Our evidence suggests that their efforts, whether they be from internal or external activities, on average, are failing. This result is all the more surprising given the active nature of external technology markets in the biopharmaceutical space. This suggests that unanticipated frictions may exist in these markets. These results could also suggest that clinical trials and FDA approval periods are more difficult to time. We leave these questions for future research. 


\section{References}

Acemoglu, D., and J. Linn. 2004. Market size in innovation: Theory and evidence from the pharmaceutical industry. Quarterly Journal of Economics 199:1049-1090.

Amoresano, G. V. 2007. Branded drug reformulation: The next brand vs. generic antitrust battleground. Food and Drug Law Journal 62:249-56.

Baker, M., R. Ruback, and J. Wurgler. 2007. Behavioral Corporate Finance: A Survey. In E. Eckbo (ed.), The Handbook of Corporate Finance: Empirical Corporate Finance. Elsevier/North Holland.

Berndt, E. R., P. M. Danzon, and G. B. Kruse. 2007. Dynamic competition in pharmaceuticals: Cross-national evidence from new drug diffusion. Managerial and Decision Economics 28:231-250.

Branstetter, L., C. Chatterjee, and M. J. Higgins. 2014. Starving (or Fattening) the Golden Goose?: Generic Entry and the Incentives for Early-Stage Pharmaceutical Innovation. Working Paper 20532, National Bureau of Economic Research. URL http://www.nber . org/papers/w20532.

Branstetter, L., C. Chatterjee, and M. J. Higgins. 2016. Regulation and welfare: Evidence from Paragraph IV generic entry in the pharmaceutical industry. The RAND Journal of Economics 47:857-890.

Bulow, J. 2004. The gaming of pharmaceutical oatents. Innovation Policy and the Economy $4: 145-187$.

Campello, M., J. R. Graham, and C. R. Harvey. 2010. The real effects of financial constraints: Evidence from a financial crisis. Journal of financial Economics 97:470-487. 
Dubois, P., O. d. Mouzon, F. Scott-Morton, and P. Seabright. 2015. Market size and pharmaceutical innovation. The RAND Journal of Economics 46:844-871.

Ellison, G., and S. F. Ellison. 2011. Strategic entry deterrence and the behavior of pharmaceutical incumbents prior to patent expiration. AEJ: Microeconomics 3:1-36.

Federal Trade Commission. 2002. Generic Drug Entry Prior to Patent Expiration: An FTC Study. U.S. Government Printing Office, Washington, D.C.

Frank, R. G., and D. S. Salkever. 1997. Generic entry and the pricing of pharmaceuticals. Journal of Economics \& Management Strategy 6:75-90.

Gormley, T. A., and D. A. Matsa. 2011. Growing out of trouble? Corporate responses to liability risk. The Review of Financial Studies 24:2781-2821.

Grabowski, H. G., and M. Kyle. 2007. Generic competition and market exclusivity periods in pharmaceuticals. Managerial and Decision Economics 28:491-502.

Hadlock, C. J., and J. R. Pierce. 2010. New evidence on measuring financial constraints: Moving beyond the KZ index. The Review of Financial Studies 23:1909-1940.

Hemphill, C. S., and B. N. Sampat. 2011. When do generics challenge drug patents? Journal of Empirical Legal Studies 8:613-649.

Hemphill, C. S., and B. N. Sampat. 2012. Evergreening, patent challenges, and effective market life in pharmaceuticals. Journal of Health Economics 31:327-39.

Higgins, M. J., and S. J. H. Graham. 2009. Balancing innovation and access: Patent challenges tip the scales. Science 326:370-371.

IMS Institute for Healthcare Informatics. 2016. Price Declines After Branded Medicines Lose Exclusivity in the US. Tech. rep. 
Lemley, M. A., and C. Shapiro. 2005. Probabilistic patents. Journal of Economic Perspectives 19:75-98.

Modigliani, F., and M. H. Miller. 1958. The cost of capital, corporation finance and the theory of investment. American Economic Review 48:261-297.

Morton, F., A. Stern, and S. Stern. 2018. The impact of the entry of biosimilars: Evidence from Europe. Review of Industrial Organization 53:73-210.

Mossinghoff, G. J. 1999. Overview of the Hatch-Waxman Act and its impact on the drug development process. Food and Drug Law Journal 54:187-94.

Murphy, S. 2017. Essays in Pharmaceutical Economics. Ph.D. thesis, MIT Dissertation: Chapter 2 .

Myers, S., and N. Majluf. 1984. Corporate financing and investment decisions when firms have information that investors do not have. Journal of Financial Economics 13:187-217.

Palermo, V., M. J. Higgins, and M. Ceccagnoli. 2019. How reliable is the market for technology? Review of Economics and Statistics 101:107-120.

Panattoni, L. E. 2011. The effect of Paragraph IV decisions and generic entry before patent expiration on brand pharmaceutical firms. Journal of Health Economics 30:126-145.

Prajapati, V., and H. Dureja. 2012. Product lifecycle management in pharmaceuticals. Journal of Medical Marketing: Device, Diagnostic and Pharmaceutical Marketing 12:150158.

Reiffen, D., and M. R. Ward. 2005. Generic drug industry dynamics. Review of Economics and Statistics 87:37-49.

Stein, J. C. 1996. Rational capital budgeting in an irrational world. Journal of Business $69: 429-455$. 
Voet, M. 2016. The Generic Challenge: Understanding Patents, FDA and Pharmaceutical Life-cycle Management. Universal-Publishers. 


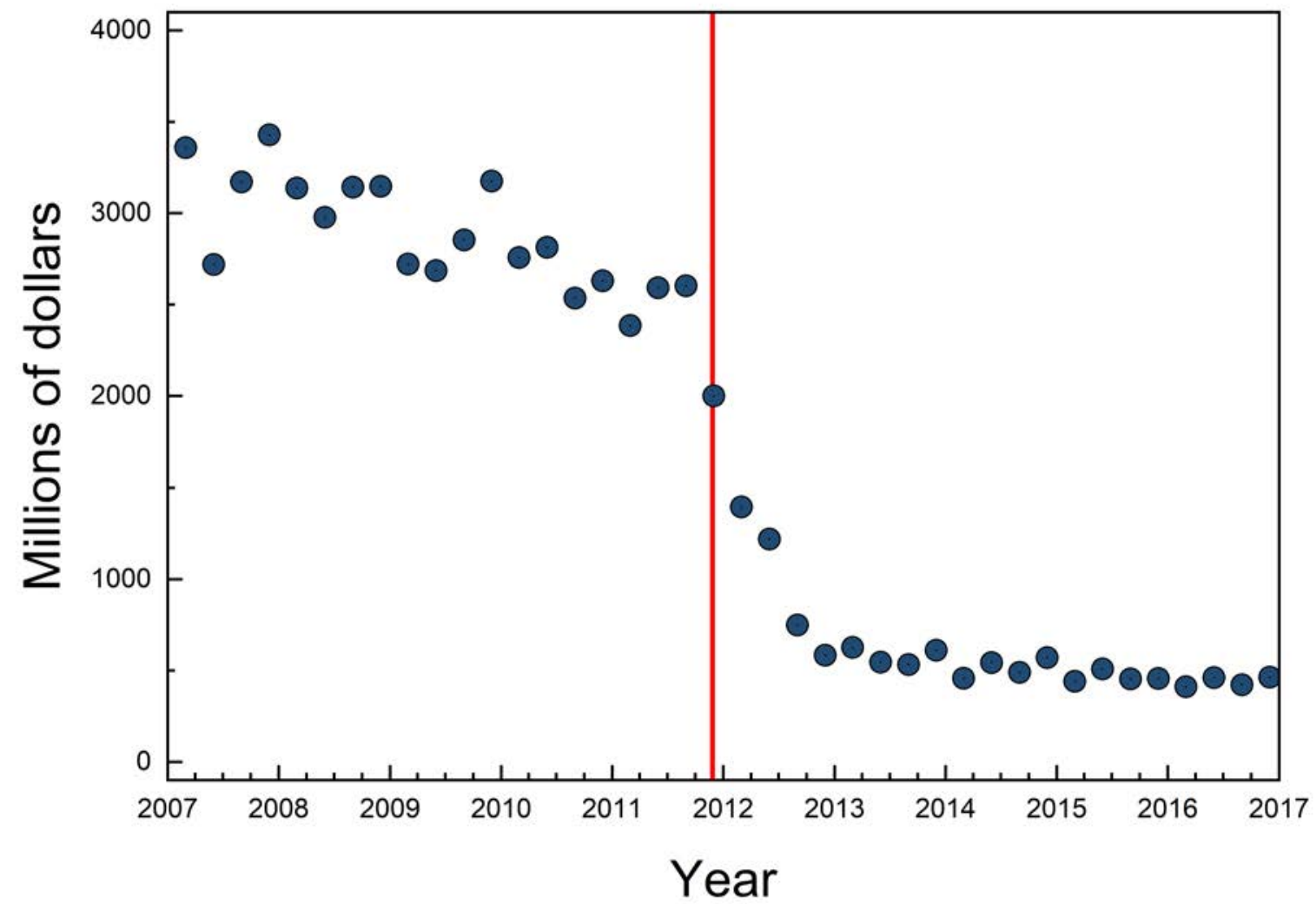

Figure 1

This figure displays quarterly global revenue in millions of U.S. dollars for Lipitor from 2007 to 2017. This drug was manufactured and marketed by Pfizer and the loss of market exclusivity occured at the end of November 2011. 


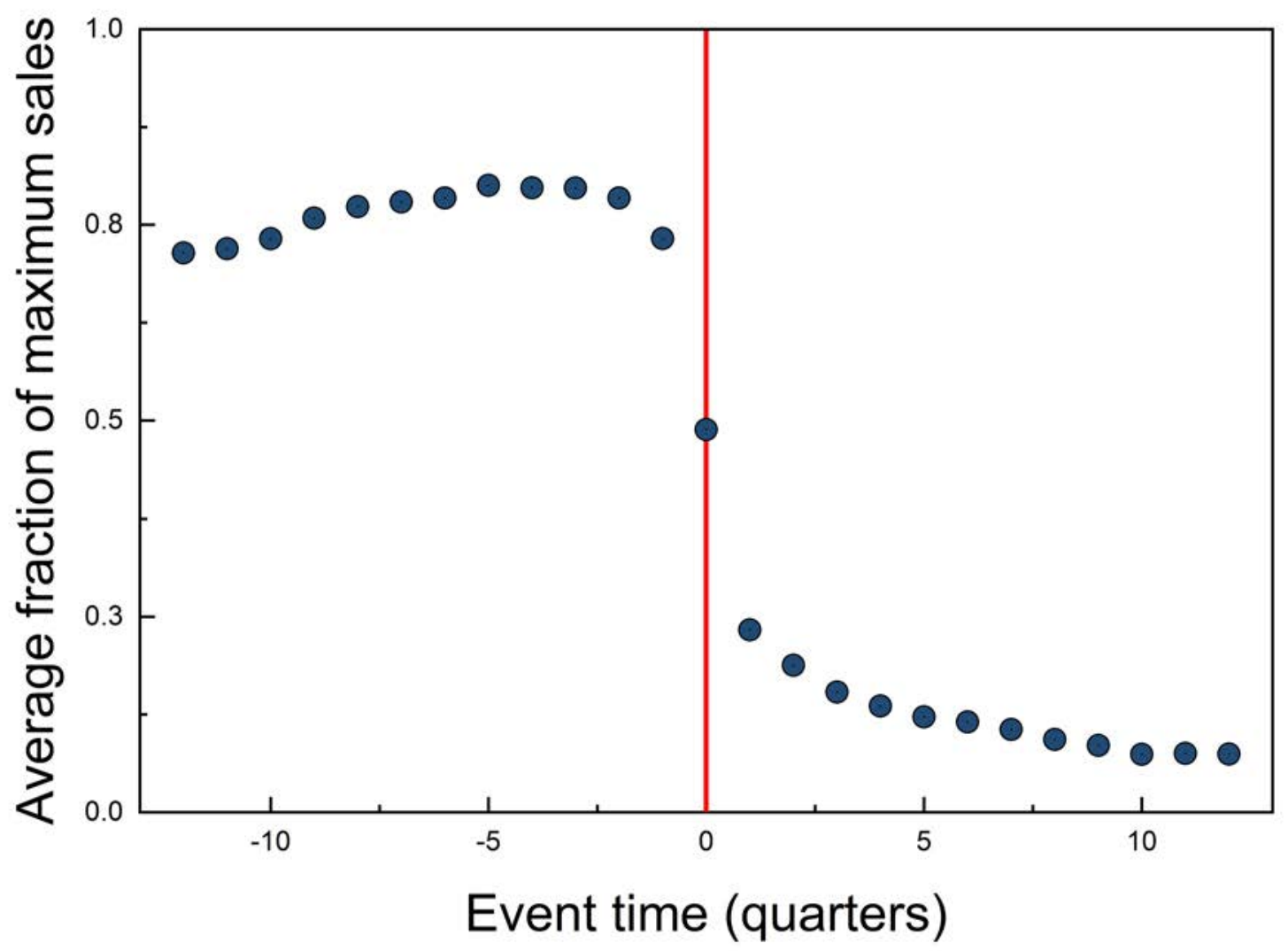

\section{Figure 2}

This figure plots the average quarterly sales as a fraction of each drug's maximum sales in event time (quarters) around the loss of market exclusivity. The data includes loss of market exclusivity events in the time period 2000 to 2010 . The vertical line in the figure is at event time $(t=0)$, which signifies the quarter when the loss of market exclusivity occurs. 
Table 1

\section{Top 25 Drugs by U.S. Sales}

This table lists the top 25 branded drugs by sales in our sample. We report U.S.-based sales as reported in IMS MIDAS. Columns 2 and 3 report the name of branded drugs and the company that holds the patent for the drugs, respectively. Column 4 reports the U.S. quarterly sales in the quarter before the loss of market exclusivity; if the sales data in that quarter is not available, we use the information as of the last available quarter before the loss of market exclusivity.

\begin{tabular}{|c|c|c|c|}
\hline Rank & Brand & Company & U.S. Sales (quarterly, \$ '000) \\
\hline (1) & $(2)$ & $(3)$ & (4) \\
\hline 1 & LIPITOR & Pfizer & $1,859,901$ \\
\hline 2 & PLAVIX & Bristol-Myers Squibb & $1,569,903$ \\
\hline 3 & SEROQUEL & Astra Zeneca & $1,042,518$ \\
\hline 4 & SINGULAIR & Merck & $1,034,608$ \\
\hline 5 & CYMBALTA & Eli Lilly & 833,599 \\
\hline 6 & ZYPREXA & Eli Lilly & 749,349 \\
\hline 7 & LEXAPRO & Forest Labratories & 726,017 \\
\hline 8 & AMBIEN & Sanofi & 618,902 \\
\hline 9 & ARICEPT & Pfizer & 469,089 \\
\hline 10 & CELEBREX & Pfizer & 433,257 \\
\hline 11 & LEVAQUIN & Johnson \& Johnson & 417,539 \\
\hline 12 & ZOLOFT & Pfizer & 414,424 \\
\hline 13 & DIOVAN HCT & Pfizer & 402,851 \\
\hline 14 & GLEEVEC & Novartis & 352,320 \\
\hline 15 & VYTORIN & Merck & 314,735 \\
\hline 16 & GEODON & Pfizer & 313,502 \\
\hline 17 & ZOCOR & Merck & 312,999 \\
\hline 18 & LOTREL & Novartis & 309,310 \\
\hline 19 & PROVIGIL & Teva Pharmaceuticals & 290,544 \\
\hline 20 & TAXOTERE & Sanofi & 286,633 \\
\hline 21 & ACIPHEX & Eisai & 266,423 \\
\hline 22 & FLONASE & GlaxoSmithKline & 239,249 \\
\hline 23 & AVELOX & Bayer & 207,686 \\
\hline 24 & PROZAC & Eli Lilly & 194,954 \\
\hline 25 & BUSPAR & Bristol-Myers Squibb & 192,192 \\
\hline
\end{tabular}


Table 2

\section{Summary Statistics}

This table provides quarterly panel summary statistics for our sample of pharmaceutical firms over the period from 1996 to 2017. The sample consists of firms in Compustat that belong to SIC code 2834, that have non-zero R\&D, an age of at least 15 years, and C.P.I-adjusted assets and quarterly revenues of at least $\$ 1$ billion and $\$ 100$ million, respectively. In Panel A, we report statistics for assets and quarterly revenues. In Panel B, we report statistics for variables that are scaled by lagged total assets. Table A.1 in the Appendix describes the definitions of all variables.

\begin{tabular}{lcccccccc}
\hline \multicolumn{7}{c}{ Panel A: Assets and Revenues } \\
\hline Variable & Mean & Std. dev. & p1 & p25 & p50 & p75 & p99 & N \\
\hline Assets & 34,444 & 41,051 & 1,089 & 3,727 & 18,933 & 49,985 & 168,244 & 2,754 \\
Revenue & 5,101 & 5,586 & 122 & 601 & 3,127 & 7,663 & 23,316 & 2,751 \\
\hline \multicolumn{7}{c}{ Panel B: Asset-scaled Variables } \\
\hline Variable & Mean & Std. dev. & p1 & p25 & p50 & p75 & p99 & No. Obs. \\
\hline Revenue / Assets & $16.89 \%$ & $7.14 \%$ & $5.11 \%$ & $11.83 \%$ & $15.65 \%$ & $20.80 \%$ & $36.85 \%$ & 2,626 \\
Net Income / Assets & $2.16 \%$ & $3.81 \%$ & $-10.57 \%$ & $0.99 \%$ & $2.33 \%$ & $3.65 \%$ & $11.41 \%$ & 2,623 \\
CapEx / Assets & $0.89 \%$ & $0.70 \%$ & $0.06 \%$ & $0.42 \%$ & $0.72 \%$ & $1.18 \%$ & $3.38 \%$ & 2,562 \\
R\&D / Assets & $2.36 \%$ & $2.10 \%$ & $0.00 \%$ & $1.07 \%$ & $2.01 \%$ & $3.01 \%$ & $10.90 \%$ & 2,628 \\
Investment / Assets & $3.25 \%$ & $2.44 \%$ & $0.35 \%$ & $1.80 \%$ & $2.76 \%$ & $3.97 \%$ & $12.77 \%$ & 2,628 \\
Dividends / Assets & $0.78 \%$ & $0.87 \%$ & $0.00 \%$ & $0.00 \%$ & $0.45 \%$ & $1.43 \%$ & $3.85 \%$ & 2,492 \\
Repurchases / Assets & $0.68 \%$ & $1.31 \%$ & $0.00 \%$ & $0.00 \%$ & $0.00 \%$ & $0.75 \%$ & $5.15 \%$ & 2,408 \\
Equity Issuance / Assets & $0.54 \%$ & $2.22 \%$ & $0.00 \%$ & $0.03 \%$ & $0.17 \%$ & $0.47 \%$ & $5.63 \%$ & 2,301 \\
Debt Issuance / Assets & $0.62 \%$ & $5.01 \%$ & $-9.39 \%$ & $-0.52 \%$ & $0.00 \%$ & $0.33 \%$ & $30.43 \%$ & 2,628 \\
Cash / Assets & $19.55 \%$ & $15.44 \%$ & $1.13 \%$ & $8.46 \%$ & $15.66 \%$ & $26.05 \%$ & $68.48 \%$ & 2,604 \\
\hline
\end{tabular}




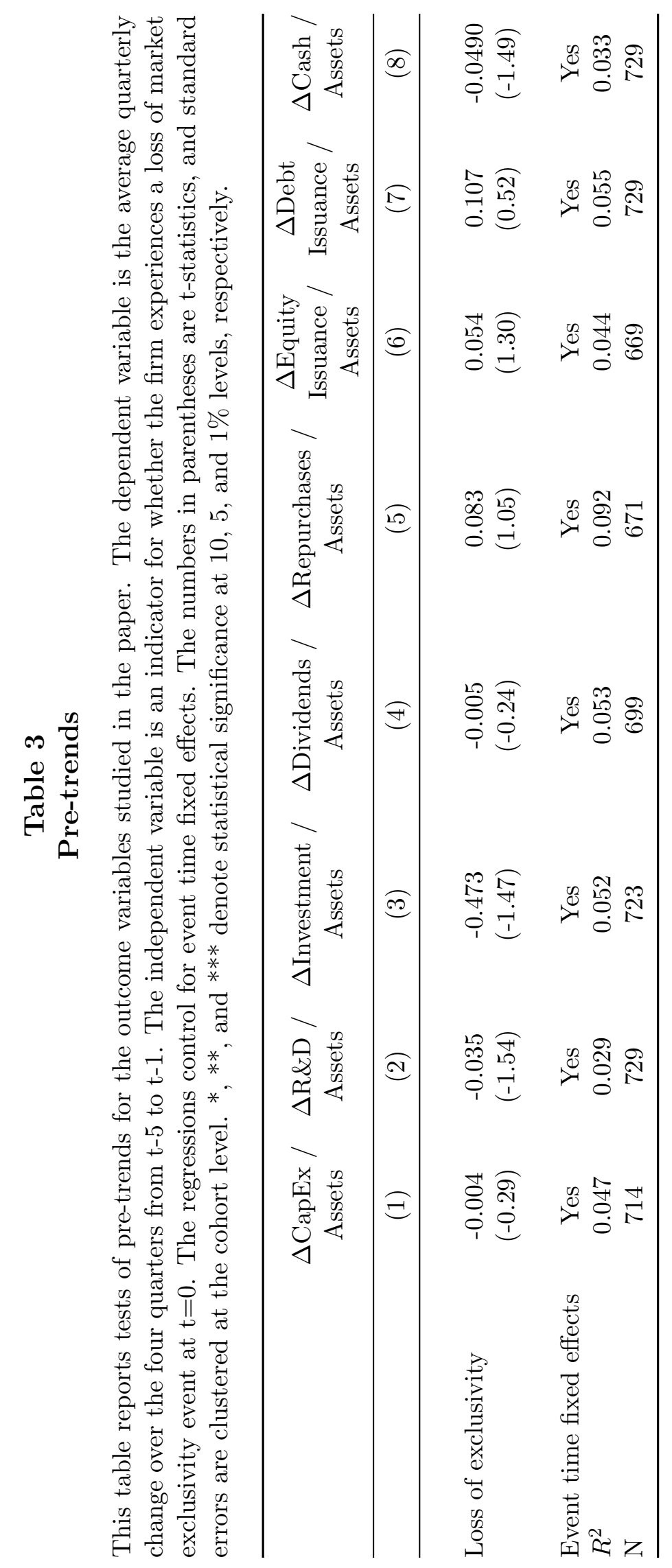


Table 4

Firm Revenue and Profitability Following the Loss of Market Exclusivity

This table reports results from difference-in-differences tests of the effect of loss of market exclusivity on firms' revenues and profit. Loss of exclusivity is an indicator of whether the firm experiences a loss of market exclusivity from a drug's patent expiring, followed by generic entry. Post is an indicator for the post-event period. We include observations between 8 quarters before and 8 quarters after the focal quarter of each cohort $(t=0)$, where "treated" firms in a cohort experience a loss of market exclusivity in the focal quarter and "control" firms do not experience such a loss. In Models 3 and 4, the independent variable is an indicator for a loss of exclusivity event for a drug representing more than $1 \%$ of the firm's sales. The sample period is from 1996 to 2017. The numbers in parentheses are t-statistics. Standard errors are double clustered at the firm and calendar-quarter levels. * $*^{* *}$, and $*^{* *}$ denote statistical significance at 10,5 , and $1 \%$ levels, respectively.

\begin{tabular}{|c|c|c|c|c|}
\hline \multirow[t]{2}{*}{ Dependent variable } & $\begin{array}{c}\text { Revenue / } \\
\text { Assets }\end{array}$ & $\begin{array}{l}\text { Net income / } \\
\text { Assets }\end{array}$ & $\begin{array}{l}\text { Revenue / } \\
\text { Assets }\end{array}$ & $\begin{array}{c}\text { Net income / } \\
\text { Assets }\end{array}$ \\
\hline & (1) & $(2)$ & $(3)$ & $(4)$ \\
\hline Loss of exclusivity* Post & $\begin{array}{c}-3.310^{* * *} \\
(-4.15)\end{array}$ & $\begin{array}{l}-1.209 \\
(-1.04)\end{array}$ & & \\
\hline $\begin{array}{l}\text { Loss of exclusivity with } \\
\text { firm's revenue }>1 \% * \text { Post }\end{array}$ & & & $\begin{array}{c}-4.216^{* * *} \\
(-4.90)\end{array}$ & $\begin{array}{c}-2.650^{* *} \\
(-2.14)\end{array}$ \\
\hline Event Quarter*Cohort fixed effects & Yes & Yes & Yes & Yes \\
\hline Firm*Cohort fixed effects & Yes & Yes & Yes & Yes \\
\hline$R^{2}$ & 0.759 & 0.412 & 0.758 & 0.413 \\
\hline $\mathrm{N}$ & 11888 & 11809 & 11640 & 11562 \\
\hline
\end{tabular}




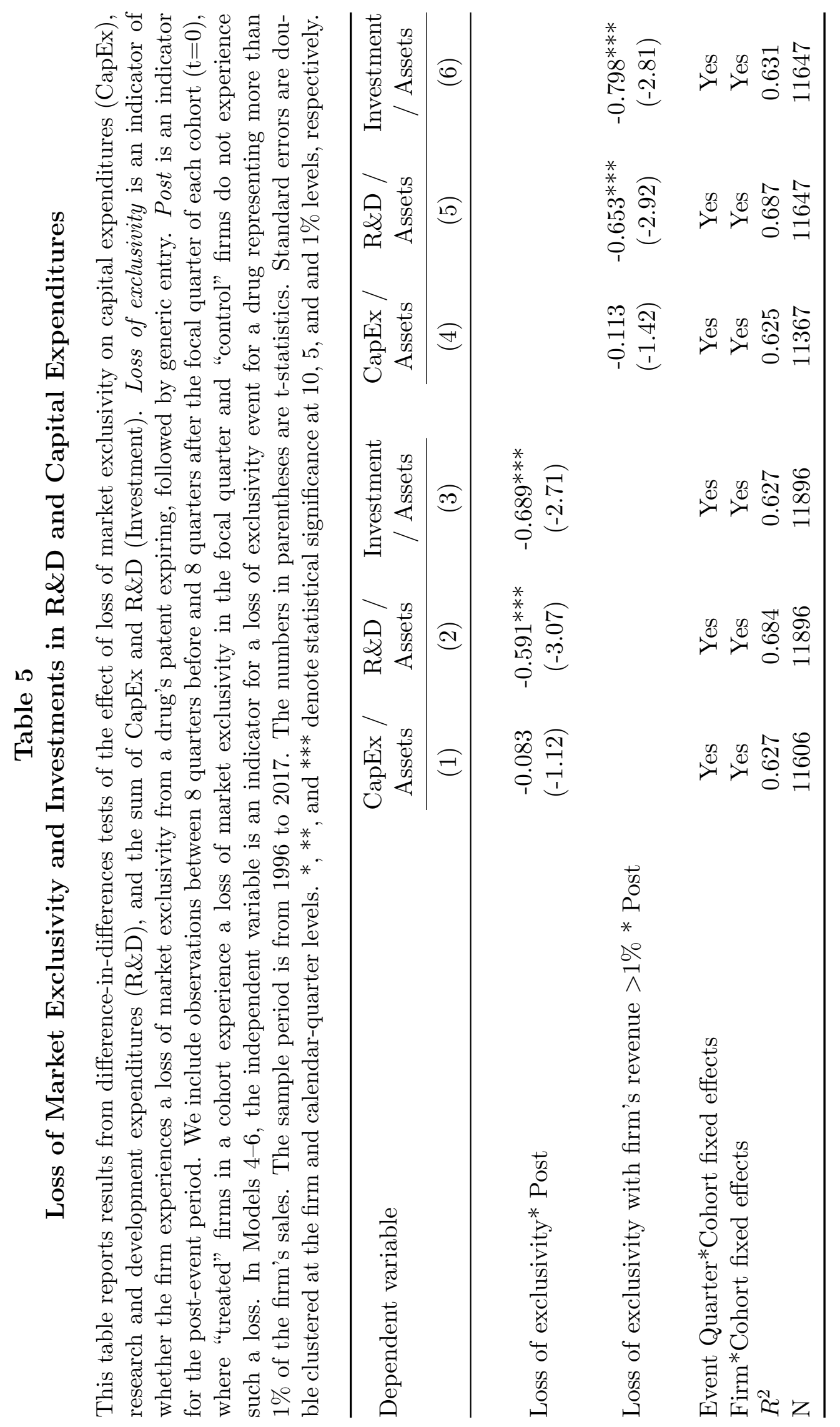




\section{Table 6}

\section{Loss of Market Exclusivity and Payout}

This table reports results from difference-in-differences tests of the effect of loss of market exclusivity on firms' payout policy. Loss of exclusivity is an indicator of whether the firm experiences a loss of market exclusivity from a drug's patent expiring, followed by generic entry. We focus on events for drugs representing more than $1 \%$ of the firm's sales. Post is an indicator for the post-event period. We include observations between 8 quarters before and 8 quarters after the focal quarter of each cohort $(\mathrm{t}=0)$, where "treated" firms in a cohort experience a loss of market exclusivity in the focal quarter and "control" firms do not experience such a loss. Total payout is the sum of dividends and repurchases. The sample period is from 1996 to 2017. The numbers in parentheses are t-statistics. Standard errors are double clustered at the firm and calendar-quarter levels. ${ }^{*},{ }^{* *}$, and ${ }^{* * *}$ denote statistical significance at 10,5 , and $1 \%$ levels.

\begin{tabular}{lccc}
\hline \multicolumn{4}{c}{ Payout policy } \\
\hline & $\begin{array}{c}\text { Dividends / } \\
\text { Assets }\end{array}$ & $\begin{array}{c}\text { Repurchases / } \\
\text { Assets }\end{array}$ & $\begin{array}{c}\text { Total Payout / } \\
\text { Assets }\end{array}$ \\
\cline { 2 - 4 } & $(1)$ & $(2)$ & $(3)$ \\
\hline Loss of exclusivity with & $0.079^{*}$ & $-0.510^{* *}$ & $-0.549^{* *}$ \\
Firm's Revenue $>1 \%$ Post & $(1.93)$ & $(-2.45)$ & $(-2.10)$ \\
Event Quarter*Cohort fixed effects & & & \\
Firm*Cohort fixed effects & Yes & Yes & Yes \\
$R^{2}$ & 0.700 & Yes & Yes \\
$\mathrm{N}$ & 11128 & 0.463 & 0.380 \\
\hline
\end{tabular}


Table 7

\section{Loss of Market Exclusivity and Financial Decisions}

This table reports results from difference-in-differences tests of the effect of loss of market exclusivity on firms' financial decisions, including equity issuance, debt issuance, and cash balances. Loss of exclusivity is an indicator of whether the firm experiences a loss of market exclusivity from a drug's patent expiring, followed by generic entry. We focus on events for drugs representing more than $1 \%$ of the firm's sales. Post is an indicator for the post-event period. We include observations between 8 quarters before and 8 quarters after the focal quarter of each cohort $(\mathrm{t}=0)$, where "treated" firms in a cohort experience a loss of market exclusivity in the focal quarter and "control" firms do not experience such a loss. The sample period is from 1996 to 2017. The numbers in parentheses are t-statistics. Standard errors are double clustered at the firm and calendar-quarter levels. ${ }^{*},{ }^{*}$, and ${ }^{* * *}$ denote statistical significance at 10,5 , and $1 \%$ levels.

\begin{tabular}{lccc}
\hline \multicolumn{4}{c}{ Issuance and cash } \\
& $\begin{array}{c}\text { Equity issuance / } \\
\text { Assets }\end{array}$ & $\begin{array}{c}\text { Debt issuance / } \\
\text { Assets }\end{array}$ & $\begin{array}{c}\text { Cash / } \\
\text { Assets }\end{array}$ \\
\cline { 2 - 4 } & $(1)$ & $(2)$ & $(3)$ \\
\hline Loss of exclusivity with & 0.052 & 0.615 & $-4.889^{* *}$ \\
Firm's Revenue $>1 \% *$ Post & $(0.33)$ & $(1.34)$ & $(-2.43)$ \\
& & & \\
Event Quarter*Cohort fixed effects & Yes & Yes & Yes \\
Firm*Cohort fixed effects & Yes & Yes & Yes \\
$R^{2}$ & 0.172 & 0.134 & 0.771 \\
$\mathrm{~N}$ & 10423 & 11647 & 11559 \\
\hline
\end{tabular}




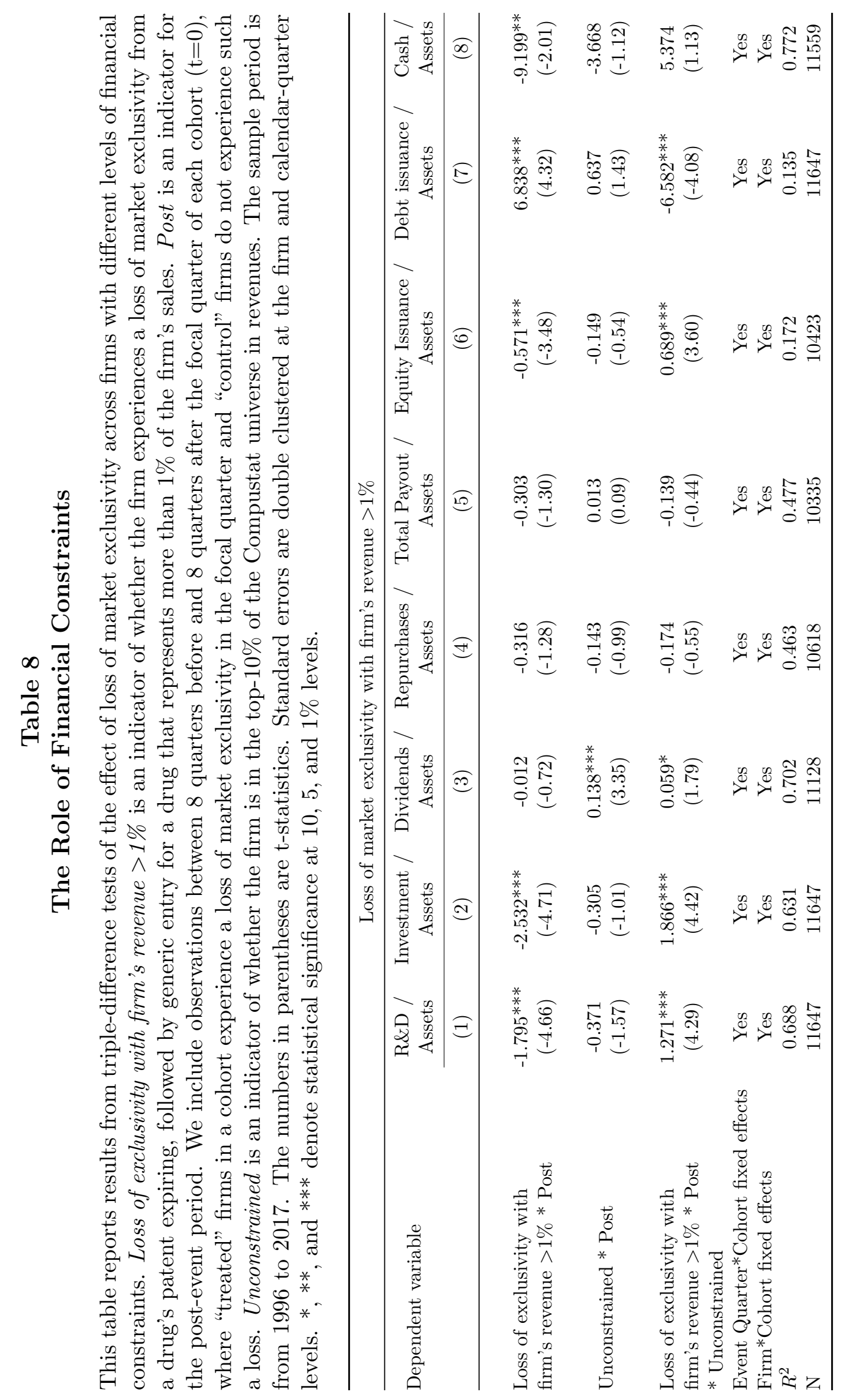




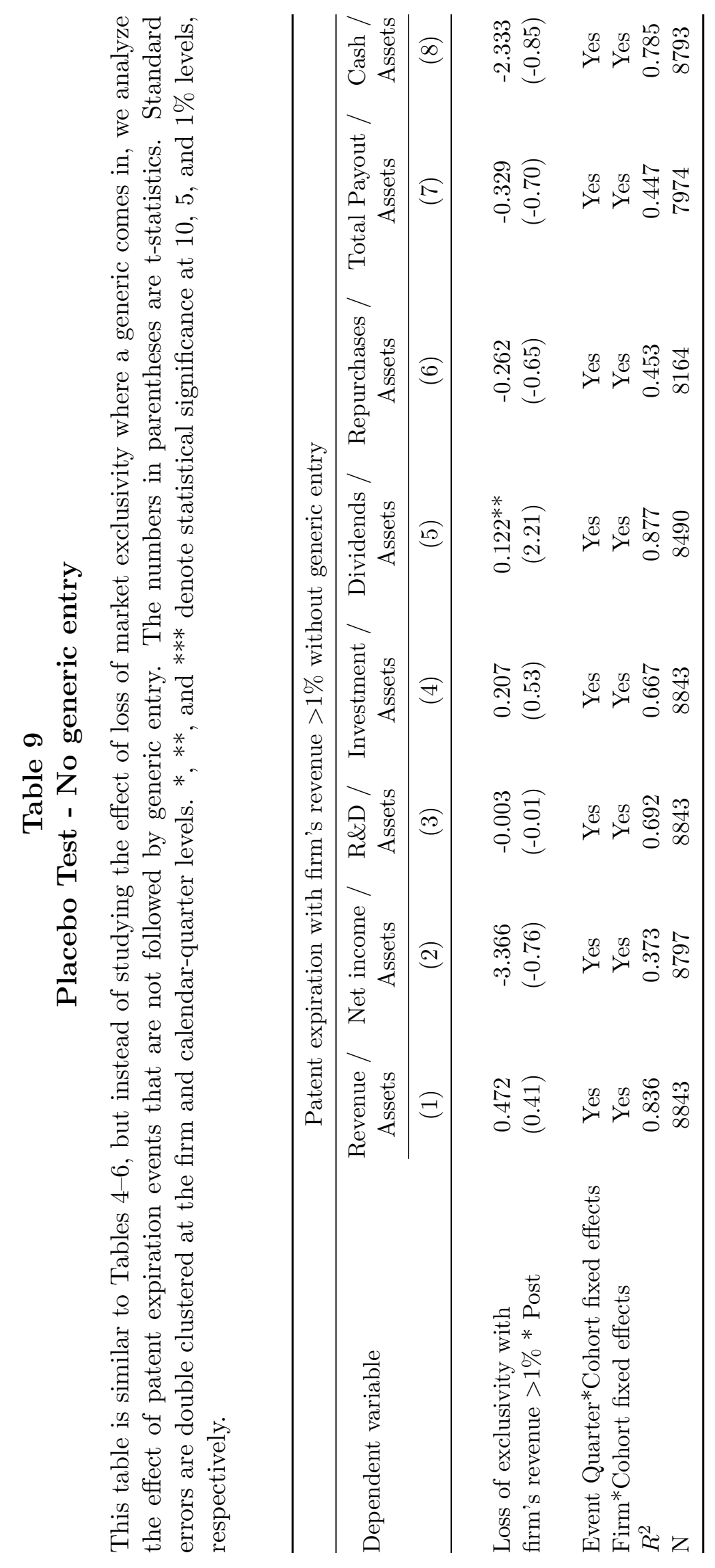




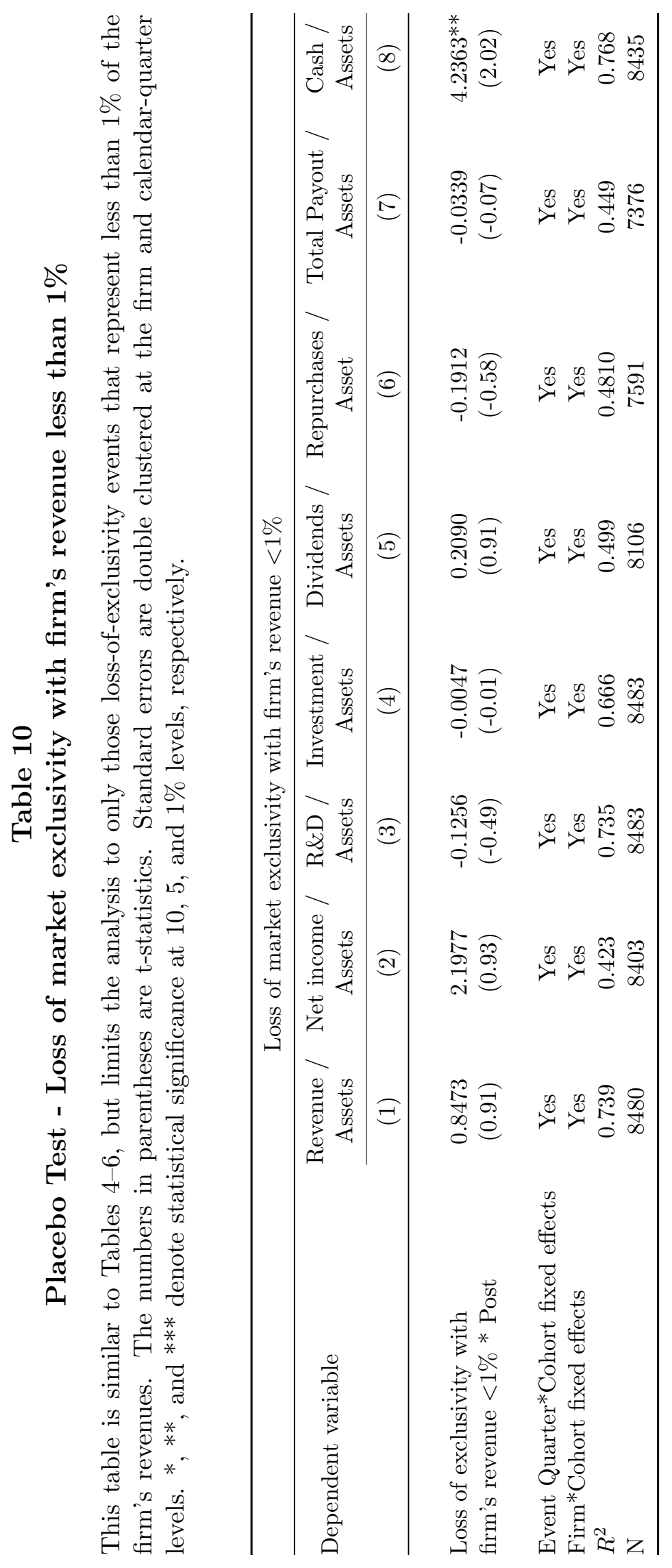




\section{Appendix}

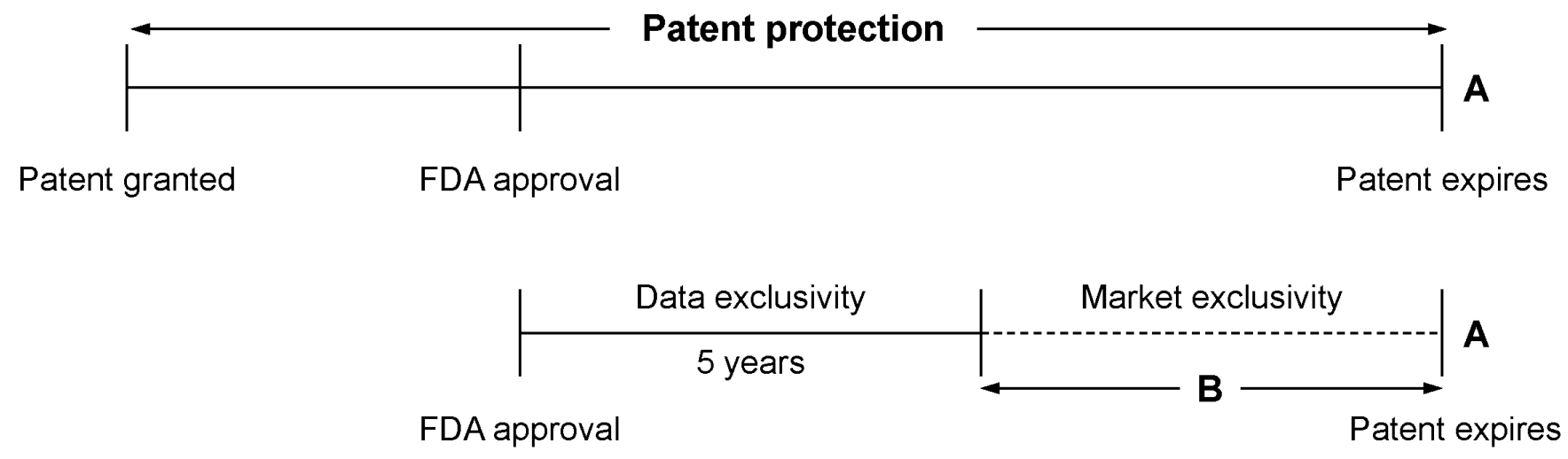

Figure A.1

Regulatory Framework

This figure demonstrates the two types of protection conferred on new chemical-based or smallmolecule drugs by the Hatch-Waxman Act. When a new chemical-based drug is approved by the FDA the first five-year period (seven years for orphan drugs and $5 \frac{1}{2}$ years for pediatric drugs) carries with it a regulatory protection called 'data exclusivity' that runs concurrent with underlying patent protection. Data exclusivity protects the underlying clinical data and provides monopoly protection in the case that a drug's underlying patent term has expired. At the conclusion of data exclusivity, a drug is protected only by its patents until they expire, a period termed 'market exclusivity'. Upon the loss of market exclusivity (A), Paragraph III generic entry may occur. Paragraph IV challenges occur only during the market exclusivity period (B). If generic manufactures are successful in the ensuing litigation, early generic entry may occur. As we note in the text, entry occurring at $\mathbf{A}$ is well anticipated, however, early generic entry during $\mathbf{B}$ is unanticipated and probabilistic. We also note that patents are generally applied for and granted well before a drug is approved by the FDA. 
Table A.1

Variable Definitions

\begin{tabular}{|c|c|}
\hline \multicolumn{2}{|r|}{ Independent Variables } \\
\hline Loss of exclusivity & $\begin{array}{l}\text { An indicator variable whether a drug's patent expires and is followed by generic } \\
\text { entry within } 6 \text { months of expiration. }\end{array}$ \\
\hline Loss of exclusivity greater than $1 \%$ & $\begin{array}{l}\text { An indicator variable whether a drug's patent expires and is followed by generic } \\
\text { entry within } 6 \text { months of expiration, and the drug represents more } \\
\text { than } 1 \% \text { of the firm's sales in the quarter before expiration. }\end{array}$ \\
\hline Post & An indicator for the post-event period. \\
\hline \multicolumn{2}{|r|}{ Outcome Variables ${ }^{20}$} \\
\hline Assets & Compustat quarterly item, total assets \\
\hline Net income & Compustat quarterly item, net income \\
\hline CapEx & Compustat quarterly item, capital expenditures \\
\hline $\mathrm{R} \& \mathrm{D}$ & Compustat quarterly item, research and development expense \\
\hline Investment & Investment is defined as capital expenditures plus $R \& D$ expenses \\
\hline Dividends & Compustat quarterly item, cash dividends \\
\hline Repurchases & $\begin{array}{l}\text { Repurchases are defined as treasury stock minus lagged treasury stock, } \\
\text { or alternatively, purchase of common and preferred stock minus sale of } \\
\text { common and preferred stock if a firm's treasury stock is zero or missing }\end{array}$ \\
\hline Total Payout & Total payout is defined as dividends plus repurchases \\
\hline Equity Issuance & Compustat quarterly item, sale of common and preferred stock \\
\hline Debt Issuance & Long-term debt issuance minus long-term debt reduction minus current debt changes \\
\hline Cash & Compustat quarterly item, cash equivalents \\
\hline
\end{tabular}

19 The outcome variables are scaled by lagged total assets one quarter before the loss of market exclusivity. 